\title{
TEM Characterization of W-O-N Coatings
}

\author{
N.M.G. Parreira ${ }^{*}$, Y.T. Pei ${ }^{* *}$, D. Galvan ${ }^{* *}$, T. Polcar ${ }^{*}$, J.Th.M. De Hosson ${ }^{* *}$ and A. Cavaleiro ${ }^{*}$ \\ * SEG-CEMUC - Department of Mechanical Engineering, University of Coimbra, 3030-788 \\ Coimbra, Portugal \\ ** Department of Applied Physics, Netherlands Institute for Metal Research, University of \\ Groningen, The Netherlands
}

Recently, a new class of coatings based on oxynitrides has drawn much attention in the research field as well as in industrial applications, as shown by either the large numbers of recent publications on TM-O-N systems (TM - transition metal) such as Ti-O-N, Zr-O-N and Ta-O-N, or the development of Si-O-N for opto-electronic devices [1]. The properties of these coatings are related to the chemical composition and the structural arrangement. However, the knowledge about the structure of TM-O-N systems is very limited, especially how the structural arrangement of the non-metallic elements is in the lattices. To the best of our knowledge, only a few studies exist on the development of structural models for oxynitrides, based on XRD and/or XPS analysis, as e.g. Si-O-N [2] and Ti-O-N [3], or on Mössbauer spectrometry for Fe-O-N [4]. TEM was used scarcely for the characterization of TM-O-N coatings possibly due to the damage of the structure by the electron-irradiation as it is reported for Cr-O-N [5]. This work is aimed at the crystallographic understanding of W-O-N sputtered films by using TEM and HR-TEM techniques for complementing the information provided by XRD characterization.

W-O-N coatings were prepared by DC reactive magnetron sputtering from a pure tungsten target in an $\mathrm{Ar}+\mathrm{O}_{2}+\mathrm{N}_{2}$ atmosphere. Starting from the $\mathrm{Ar}+\mathrm{N}_{2}$ atmosphere, the progressively increased flow of oxygen to the discharge allowed varying the chemical composition of the coatings from high to low N/O ratios. The chemical composition and the structure of the films were analysed by electron probe microanalysis (EPMA) and X-ray diffraction (XRD - with Co K $\alpha$ radiation), respectively. The structural analysis was complemented by (high-resolution) transmission electron microscopy and electron diffraction (HRTEM / ED - operating at $200 \mathrm{kV}$ ). Further details on the deposition procedures can be found in previous authors papers $[6,7]$

Fig. 1 shows the chemical composition and XRD patterns of W-O-N coatings. As expected, there is an inverse trend between $\mathrm{W}$ and $\mathrm{O}$ contents. That is to say, the content of $\mathrm{W}$ steadily decreases whereas the $\mathrm{O}$ content increases with increasing $\mathrm{O}_{2}$ flow rate, until reaching the composition ( 24 at.\% $\mathrm{W}$ and 71 at.\% $\mathrm{O}$ ) very close to the stoichiometry of $\mathrm{WO}_{3}$ compound. However, for the same $\mathrm{O}_{2}$ flow rate variation, the $\mathrm{N}$ content only starts to decrease at $f \mathrm{O}_{2}=6 \mathrm{sccm}$, below of which the $\mathrm{N}$ content remains approximately constant. These results shows that in all the coatings the ratio between $\mathrm{W}$ and $\mathrm{N} / \mathrm{O}$ is lower than the one regarding the stoichiometry of $\mathrm{WN}$ and $\mathrm{WO}_{3}$ compounds [6]. With increasing $f \mathrm{O}_{2}$ a progressive decrease of the crystallinity could be detected with some coatings even showing typical XRD-amorphous patterns. For $f \mathrm{O}_{2}$ up to $6 \mathrm{sccm}$ $\left(\mathrm{N} \geq 47\right.$ at.\%) several well-defined diffraction peaks could be detected at $2 \theta$ close to 42,50 and $75^{\circ}$. These peaks are indexed to the nitrogen rich phases, $\beta-\mathrm{W}_{2} \mathrm{~N}, \delta-\mathrm{WN}$ or $\mathrm{W}_{0.62}(\mathrm{O}, \mathrm{N})$, as it was discussed in Ref. [6]. Moreover, for $f \mathrm{O}_{2} \geq 3 \mathrm{sccm}$, the coatings showed a broad diffraction peak centred at $2 \theta \approx 30^{\circ}$ which is attributed to a quasi-crystalline $\mathrm{W}-\mathrm{O}$ phase. For $\mathrm{W}-\mathrm{O}-\mathrm{N}$ coatings deposited with $\mathrm{fO}_{2} \geq 7 \mathrm{sccm}$, the structure exhibited a nanocrystalline $\mathrm{WO}_{3}$ structure [6]. The evolution of the structure with increasing $\mathrm{O}$ in the reactive gases mixture is summarized as:

$$
\beta-\mathrm{W}_{2} \mathrm{~N} \rightarrow \delta-\mathrm{WN} \rightarrow \mathrm{W}_{0.62}(\mathrm{~N}, \mathrm{O})+\text { amorphous } \mathrm{W}-\mathrm{O} \rightarrow \text { nanocrystalline } \mathrm{W}(\mathrm{O}, \mathrm{N})_{3}
$$


From the XRD results, two main points remain unclear and have motivated further characterization of selected coatings by more sophisticated techniques:

1) What is the volume fraction of the crystalline nitride phase and the amorphous W-O phase in the $\mathrm{W}_{27} \mathrm{O}_{26} \mathrm{~N}_{47}$ coating?

2) What is the crystallographic difference between the coatings $\mathrm{W}_{24} \mathrm{O}_{38} \mathrm{~N}_{38}$ and $\mathrm{W}_{24} \mathrm{O}_{72} \mathrm{~N}_{04}$ that exhibited similar XRD patterns but different $\mathrm{N}$ contents?

For the coating $\mathrm{W}_{27} \mathrm{O}_{26} \mathrm{~N}_{47}$, the electron diffraction pattern shown in Fig. 1b confirms the XRD analysis and reveals the presence of (oxy)nitride nanocrystallites. The sharp ring patterns at the reciprocal distance of $4.18,4.85,6.86,8.05$ and $9.70 \mathrm{~nm}^{-1}$ fit perfectly to the first five strong diffractions of both cubic $\beta-\mathrm{W}_{2} \mathrm{~N}$ phase (ICDD card No. $25-1257$ ) and $\mathrm{W}_{0.62}(\mathrm{~N}, \mathrm{O})$ phases (ICDD card No. $25-0254 \& 89-4762$ ). Because of the high oxygen content, $\mathrm{W}_{0.62}(\mathrm{~N}, \mathrm{O})$ phase seems to be more favoured in this case. In addition, there are several rather broad/diffuse rings at the reciprocal distance of $3.15,9.7,10.9$ and $12.0 \mathrm{~nm}^{-1}$, of which the first one corresponds to an interplanar distance of $0.317 \mathrm{~nm}$. This distance is two times of the $\mathrm{W}-\mathrm{O}$ bonds when one oxygen atom is singly bonded to the tungsten atom, or corresponding to the strongest (200) diffraction of hexagonal $\mathrm{WO}_{3}$ phase (ICDD card No. 85-2459). The former case can only occur in amorphous $\mathrm{WO}_{3}$ where oxygen is deficient or in the presence of impurities such $\mathrm{Na}^{+}$[8]. The large ratio between $\mathrm{O}+\mathrm{N}$ and $\mathrm{W}$ $(>2.5)$ suggests that $\mathrm{N}$ is present in the amorphous $\mathrm{WO}_{3}$ phase and thus hinders the crystallization. The HR-TEM micrograph in Fig. 2 reveals that nanocrystallites of about $8 \mathrm{~nm}$ in diameter are embedded in the amorphous matrix. With numerical analysis, the FFT images from the crystalline and quasi-amorphous regions are shown in the inserts (a) and (b) of Fig. 2. From the insert (a), it is possible to recognize an f.c.c. $\mathrm{NaCl}$ structure by the $\{111\},\{200\}$ and $\{220\}$ plans. However the small difference in the lattice parameter between the $\beta-\mathrm{W}_{2} \mathrm{~N}$ and the $\mathrm{W}_{0.62}(\mathrm{~N}, \mathrm{O})$ phases $(0.4126 \mathrm{~nm}$ versus $0.4138 \mathrm{~nm}$ ) does not allow an unambiguous identification.

In the case of coating $\mathrm{W}_{25} \mathrm{O}_{38} \mathrm{~N}_{37}$, the analysis by XRD and electron diffraction gives the same results: no long range ordering can be identified. By deconvolution of the intensity line profile it is possible to distinguish three diffuse rings centred at 2.66, 3.8 and $5.6 \mathrm{~nm}^{-1}$, corresponding to interplanar distances of $0.375,0.263$ and $0.179 \mathrm{~nm}$ (Fig. 1c), which can be identified as the plans $\{200\},\{220\}$ and $\{400\}$, respectively, of $\mathrm{m}-\mathrm{WO}_{3}$ phase (ICCD card No. 83-0950). Moreover, a more intense ring centred at $3 \mathrm{~nm}^{-1}$ represents the amorphous $\mathrm{WO}_{3}$ phase, as discussed in the previous paragraph. Even using HT-TEM (see Fig. 3a), only some "clusters" with a diameter smaller than $2 \mathrm{~nm}$, that are difficult to identify, suggest the existence of short range order (the existence of the diffuse diffraction rings). The no-detection of any ring (even diffuse) that could be indexed as a $\mathrm{W}-\mathrm{N}$ phase suggests that $\mathrm{N}$ is saturated in the $\mathrm{W}-\mathrm{O}$ nanocrystalline/amorphous phase.

The coating $\mathrm{W}_{24} \mathrm{O}_{71} \mathrm{~N}_{05}$ with similar XRD pattern but lower nitrogen content was also analysed by HR-TEM. Exactly the same aspect as $\mathrm{W}_{25} \mathrm{O}_{38} \mathrm{~N}_{37}$ was achieved, when high resolution and FFT were used. However, after a few minutes of e-beam irradiation, a structural modification was observed. Such a phenomenon has already been observed in W-O [9] or in Cr-O-N [5] thin films. However, it should be pointed out that this modification did never happen in the TEM study of other W-O-N coatings, particularly in the coating $\mathrm{W}_{25} \mathrm{O}_{38} \mathrm{~N}_{37}$. After the crystallization (Fig.3b), the structure of the coating $\mathrm{W}_{24} \mathrm{O}_{71} \mathrm{~N}_{05}$ can be identified as the orthorhombic $\mathrm{W}_{3} \mathrm{O}_{8}$ phase (ICDD card No. 81-2262), where the reflections of the plans $\{130\}$ and $\{200\}$ were indexed. This different behaviour suggests that the presence of higher amounts of $\mathrm{N}$ in the quasi-amorphous $\mathrm{WO}_{3}$ phase, as in the coating $\mathrm{W}_{25} \mathrm{O}_{38} \mathrm{~N}_{37}$, contributes to its stability and retards crystallization.

In this work, the structural evolution of $\mathrm{W}-\mathrm{O}-\mathrm{N}$ coatings could be summarized as: $\beta-\mathrm{W}_{2} \mathrm{~N} \rightarrow$ $\delta-\mathrm{WN} \rightarrow \mathrm{W}_{0.62}(\mathrm{~N}, \mathrm{O})+$ amorphous $\mathrm{W}-\mathrm{O} \rightarrow$ nanocrystalline $\mathrm{W}(\mathrm{O}, \mathrm{N})_{3}$. Further studies using HR- 
TEM showed that: (1) $\mathrm{W}_{27} \mathrm{O}_{26} \mathrm{~N}_{47}$ is composed of nanocrystalline $\mathrm{W}_{0.62}(\mathrm{~N}, \mathrm{O})$ grains embedded in a quasi-amorphous oxide matrix, (2) $\mathrm{W}_{25} \mathrm{O}_{38} \mathrm{~N}_{37}$ is characterized by a full amorphous structure and, (3) $\mathrm{W}_{24} \mathrm{O}_{71} \mathrm{~N}_{05}$ exhibits also an amorphous structure but may crystallize after some minutes of ebeam irradiation, suggesting that the saturation of nitrogen could stabilize the amorphous phase.

[1] S. Venkataraj, D. Severin, S.H. Mohamed, J. Ngaruiya, O. Kappertz, M. Wuttig, Thin Solid Films 502 (2006) 228.

[2] V.A. Gritsenko, R.W.M. Kwok, H. Wong, J.B. Xu, Journal of Non-Crystalline Solids 297 (2002) 96.

[3] J. Guillot, J.-M. Chappé, O. Heintz, N. Martin, L. Imhoff, J. Takadoum, Acta Mater. 54 (2006) 3067.

[4] M. Grafouté, C. Petitjean, C. Rousselot, J.F. Pierson, J.M. Grenèche, Journal of Physics: Condensed Matter 19 (2007) 226207.

[5] C. Mitterbauer, W. Grogger, P. Wilhartitz, F. Hofer, Micron 37 (2006) 385.

[6] N.M.G. Parreira, T. Polcar, N. Martin, O. Banakh, A. Cavaleiro, Plasma Processes and Polymers 4 (2007) S69.

[7] D. Galvan, Y.T. Pei, J.T.M. De Hosson, Acta Mater. 53 (2005) 3925.

[8] G.A. de Wijs, R.A. de Groot, Phys. Rev. B 60 (1999) 16463.

[9] A. Antonaia, M.L. Addonizio, C. Minarini, T. Polichetti, M. Vittori-Antisari, Electrochimic Acta 46 (2001) 2221.

[10] This work was supported by the European Union through the NMP3-CT-2003-505948 project "HARDECOAT" and by FCT Portugal through the POCI/V.5/A0034/2005 project and the PhD Scholarship SFRH/BD/16528/2004 attributed to the author Parreira.

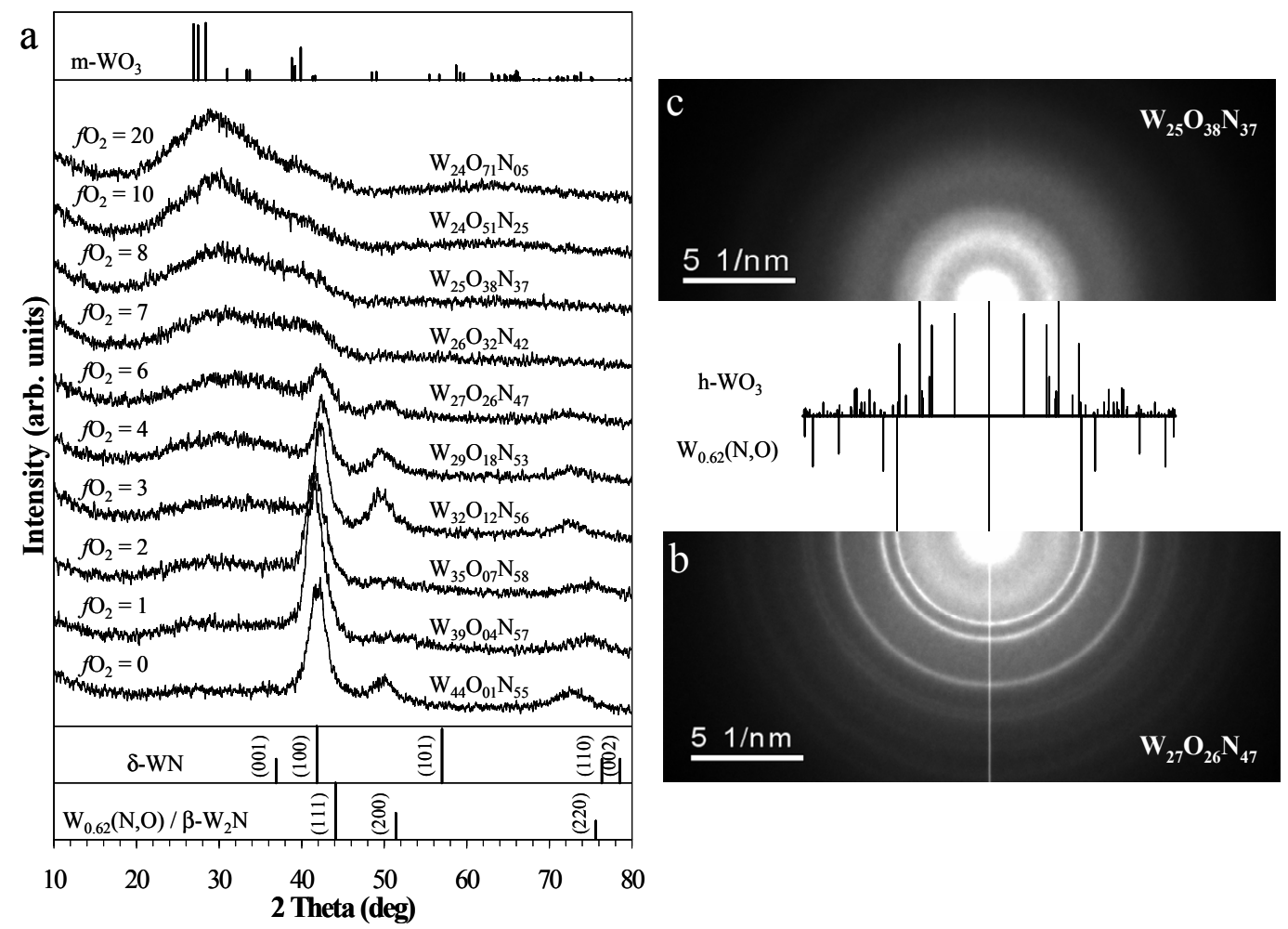

Fig. 1. (a) XRD pattern of the W-O-N coatings deposited with increasing oxygen flow [6]. Selected area electron diffraction patters of the coatings $\mathrm{W}_{27} \mathrm{O}_{26} \mathrm{~N}_{47}$ (b) and $\mathrm{W}_{25} \mathrm{O}_{38} \mathrm{~N}_{37}$ (c). 

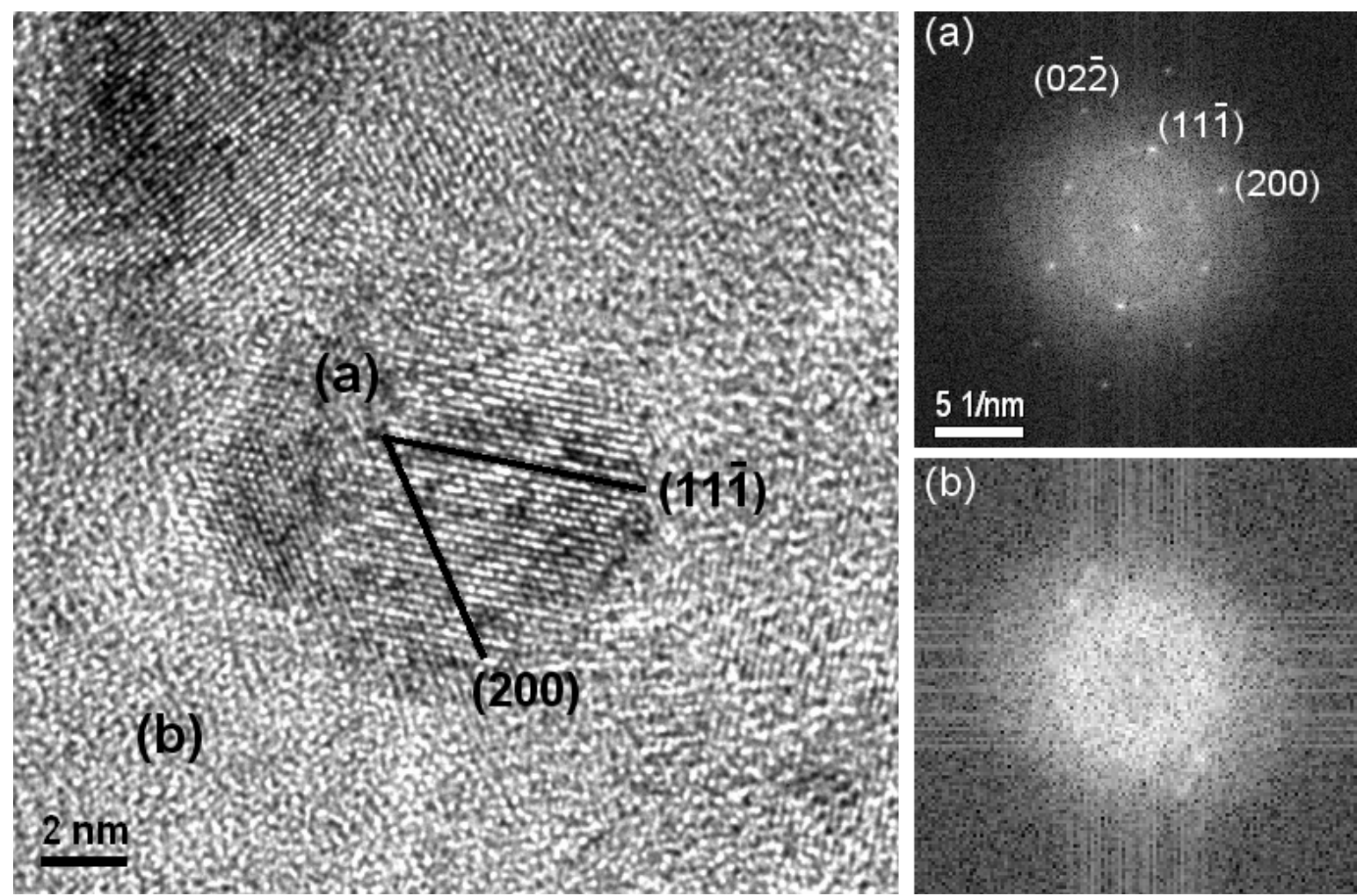

Fig. 2. HR-TEM micrograph of coating $\mathrm{W}_{27} \mathrm{O}_{26} \mathrm{~N}_{47}$ showing nanocrystallites embedded in amorphous matrix. The inserts (a) and (b) show the diffraction patterns obtained by FFT on the crystalline and quasi-amorphous areas indicated in the micrograph.
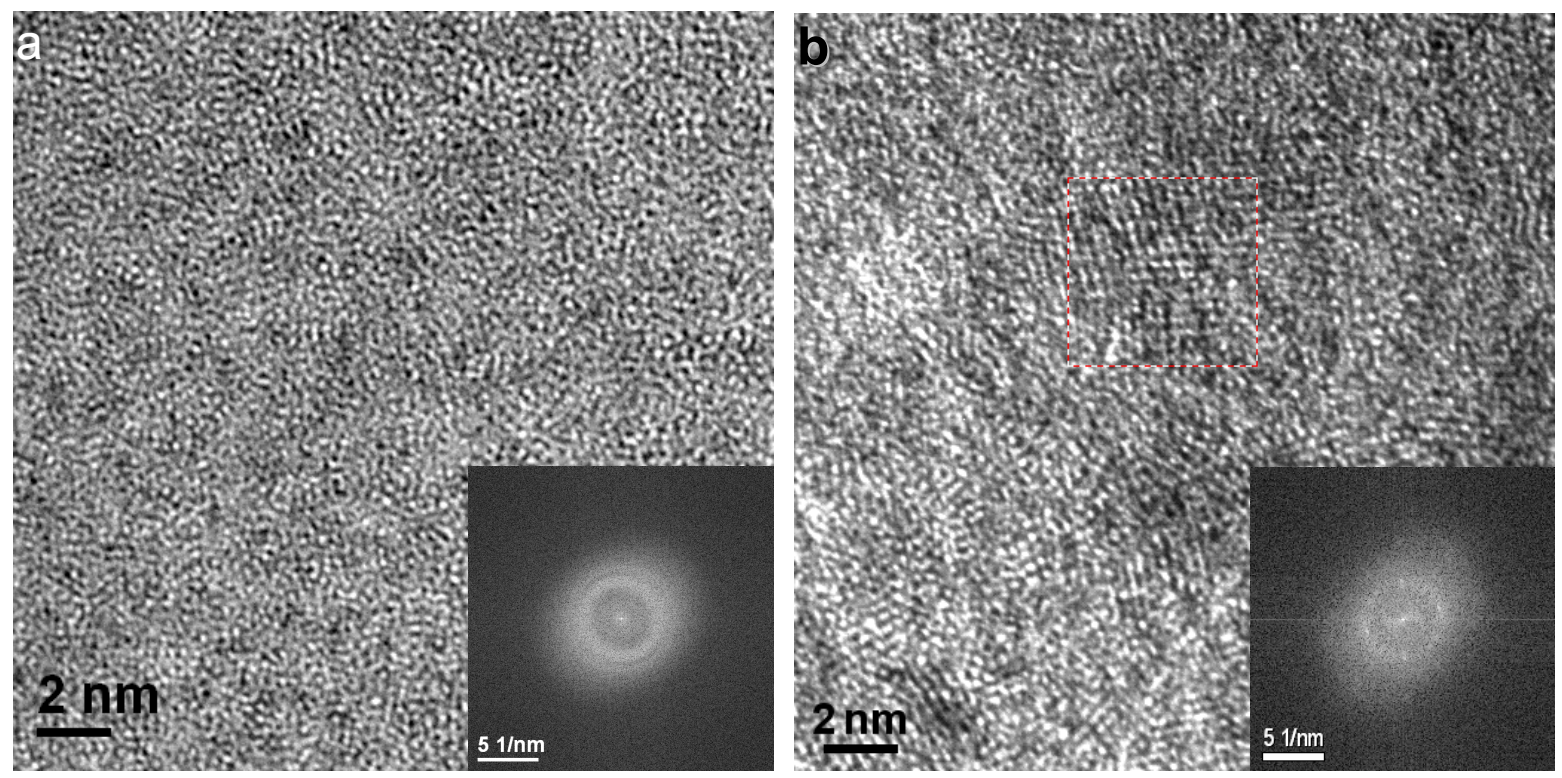

Fig. 3. HR-TEM micrograph of coatings: (a) $\mathrm{W}_{25} \mathrm{O}_{38} \mathrm{~N}_{37}$ and (b) $\mathrm{W}_{24} \mathrm{O}_{71} \mathrm{~N}_{05}$ partly crystallized due to the irradiation of electron beam. 